\title{
Gestational trophoblastic diseases in a teaching hospital in northern, Nigeria
}

\author{
Ibrahim Yakasai ${ }^{1}$, Idris Abubakar ${ }^{1}$, Yunus Eze ${ }^{2}$ \\ ${ }^{1}$ Department of Obstetrics and Gynaecology, Bayero University Kano/Aminu Kano Teaching Hospital Kano, Nigeria \\ ${ }^{2}$ Aminu Kano Teaching Hospital Kano, Nigeria \\ Email address: \\ Ibrahimyakasai57@hotmail.com (I. Yakasai), idinkano@yahoo.com (I. Abubakar), yunuse@yahoo.com (Y. Eze) \\ To cite this article: \\ Ibrahim Yakasai, Idris Abubakar, Yunus Eze. Gestational Trophoblastic Diseases in a Teaching Hospital in Northern, Nigeria. American \\ Journal of BioScience. Vol. 3, No. 1, 2015, pp. 7-10. doi: 10.11648/j.ajbio.20150301.12
}

\begin{abstract}
Background: Gestational trophoblastic diseases (GTD) is a spectrum of pregnancy-related premalignant disorders of complete and partial hydatidiform mole, and the malignant disorders of invasive mole, choriocarcinoma, and the rare placental-site trophoblastic tumour. Objective: This study was carried out to determine the incidence of gestational trophoblastic disease, the clinical features and management outcome at the Aminu Kano Teaching Hospital, Kano, Nigeria. Materials and Methods: This was a retrospective study of the demographic and clinical data as well as management outcome of all patients with gestational trophoblastic disease managed between January, 2008 and December, 2012 at the Aminu Kano Teaching Hospital. Kano,Nigeria Results: There were 103 cases of GTD and 22,680 deliveries; giving an incidence of GTD as 4.5 per 1000 deliveries. Among them, 69 (67.0\%) cases were hydatidiform mole while Choriocarcinoma was diagnosed in 34 cases $(33.0 \%)$. The antecedent pregnancy among the cases of choriocarcinoma were hydatidiform mole in 18 cases $(52.9 \%)$, miscarriage in 10 cases $(29.4 \%)$ and ectopic pregnancy in 1 case $(3.0 \%)$ and full term pregnancy in 5(14.7\%) patients. GTD was commoner at the extremes of reproductive age. Hydatidiform mole was high 37(53.6\%) in those aged 24 years and below, while choriocarcinoma was high $13(38.2 \%)$ in 45 - 49 years age group. The most common presenting symptom was vaginal bleeding occurring in all the cases, while anaemia was the most common complication. Suction evacuation and follow up $(67.0 \%)$ was the mode of treatment in all cases of molar pregnancy. Only cases of choriocarcinoma $34(33.0 \%)$ had chemotherapy, $11(32.4 \%)$ cases had single agent while 23 cases $(67.6 \%)$ had multi-agent chemotherapy. There were seven maternal deaths in this study, given a case fatality of $6.8 \%$. Conclusion: The incidence of GTD in this study was 4.5 per 1000 deliveries. Vaginal bleeding was the commonest presenting symptom. Early diagnosis and appropriate treatment of this disease has an excellent prognosis, while late presentation was associated with high maternal mortality as found in this study.
\end{abstract}

Keywords: Molar Pregnancy, Choriocarcinoma, Maternal Mortality

\section{Introduction}

Gestational trophoblastic disease (GTD) encompasses a range of pregnancy related disorders, consisting of the premalignant disorders of complete and partial hydatidiform mole, and the malignant disorders of invasive mole, choriocarcinoma, and the rare placental-site trophoblastic tumour $^{1}$. These malignant forms are termed gestational trophoblastic neoplasia $(\mathrm{GTN})^{1}$. Although GTN typically follows a molar pregnancy, they can occur after any gestational event ${ }^{2,3}$.

The incidence of GTD varies in different regions of the world. The incidence of molar pregnancies in the United States is 1 per 1000 pregnancies, in the United Kingdom 1.5 per 1000, and in Japan 2 per $1000^{2,3,4}$. In Nigeria, incidences of 3.8 per 1000 and 4.7 per 1000 deliveries were reported from Northeast and Southeast respectively ${ }^{5,6}$. In general, areas with high incidence of molar pregnancies have proportionately greater incidence of choriocarcinoma arising from hydatidiform mole ${ }^{4}$.

The aetiology of gestational trophoblastic disease is not well understood. However, hydatidiform moles affect women throughout the reproductive age range but are more common at the extremes of the range ${ }^{7}$. Women under 16 have a six times higher risk of developing the disease than those aged 16-40, and women who conceive aged 50 years or more have a one in three chance of having a molar pregnancy ${ }^{7}$. There is higher incidence in women of Far Eastern origin and Africa than for white women from the United Kingdom and other 
Western countries ${ }^{7,8}$. The reasons for this are not clear but might reflect low socioeconomic status and diet deficient in protein, folic acid and carotene $e^{4,6,8}$.

Patients with hydatidiform mole usually present with amenorrhoea, vaginal bleeding and spontaneous passage of grape-like vesicles. There may also be hyperemesis gravidarum, Examination may reveal a doughy uterus which may be large for the gestational age. There may be adnexal masses as a result of bilateral theca lutein cyst and rarely, they may present with features of thyrotoxicosis and preeclampsia in the first half of pregnancy ${ }^{9}$. High serum and urinary $\beta$ human chorionic gonadotrophin $(\beta-h C G)$ levels are characteristics of the disease. However, ultrasonography which shows classic "snowstrom" appaerance is a reliable and sensitive technique for a pre-evacuation diagnosis but the definitive diagnosis is made by histological examination of the products of conception ${ }^{8}$. The clinical course is defined by the patient's serum $\beta$-hCG curve after evacuation of the mole $\mathrm{e}^{9,10}$. In $80 \%$ of patients with hydatidiform mole, serum $\beta$-hCG levels steadily drop to normal within 8-12 weeks after evacuation of the molar pregnancy ${ }^{9,10}$. However, women who have the malignant form of GTD may show $\beta$-hCG titres, which either plateau or rise and remain elevated beyond 8 weeks ${ }^{11}$. New pregnancy and or presence of other tumours like non gestational choriocarcinoma, embryonal cancer and polyembryomas that secrete $\beta$-hCG for example, could confuse management ${ }^{4}$.

Gestational trophoblastic neoplasia (invasive mole or choriocarcinoma) follows complete mole in $15-20 \%$ of cases and less than $5 \%$ of partial moles will develop post molar $\mathrm{GTN}^{4,12}$. The World Health Organisation has proposed prognostic risk scoring system which reliably assesses the potential for resistance to chemotherapy ${ }^{4,7}$. Score $<7$ represents low risk of resistance to chemotherapy while score $\geq 7$ represents high risk $^{8,12,13}$. GTD are generally highly responsive to chemotherapy ${ }^{11}$.However, hysterectomy remains an option for good surgical candidates not desirous of future pregnancy, women who are older and more likely to develop malignant sequelae, presence of placenta site trophoblastic tumour and cases complicated by haemorrhage ${ }^{9}$. Hysterectomy does not eliminate the need for careful follow up with $\beta$-hCG testing, although the likelihood of metastatic disease following hysterectomy for GTD decreases from $20 \%$ to $3-5 \%{ }^{8,13}$. Early stage GTN disease is often cured with single-agent chemotherapy ${ }^{14,15}$. In contrast, advanced stage disease requires multi-agent combination chemotherapeutic regimens to achieve a cure $e^{7,14,15}$. GTD is one of the few highly curable human tumors, even in the setting of advanced disease and widespread metastases.

This study was carried out to determine the incidence of gestational trophoblastic disease, the clinical features and management outcome at the Aminu Kano Teaching Hospital, Kano, Nigeria.

\section{Materials and Methods}

This was a retrospective descriptive study carried out at the Aminu Kano Teaching Hospital, Kano Nigeria. Kano is in the Northern part of Nigeria where the tribe was mostly hausas. The case records of all the patients with gestational trophoblastic disease managed between January, 2008 and December, 2012 were retrieved. The outcome measures were the socio-demographic characteristics of the patients, clinical presentation, modalities of treatment, management outcome, complications, and follow up. The data obtained were analyzed using SPSS, and presented in tabular form using frequencies and percentages, mean and standard deviation..

\section{Results}

There were 103 cases of GTD out of 4,529 gynaecological admissions during the study period, there by constituting $2.3 \%$ to total gynaecological admissions. There were 22,680 deliveries; hence the incidence of GTD was 4.5 per 1000 deliveries. Of 103 cases of GTD, 69(66.9\%) were hydatidiform mole and 34 (33.1\%) were choriocarcinoma.

The age range of the patients was $15-59$ with a mean of $37 \pm 5$ years. GTD was commoner at the extremes of reproductive age. Hydatidiform mole was high $37(53.6 \%)$ in those aged 24 years and below, while choriocarcinoma was high $13(38.2 \%)$ in 45 - 49 years age group.

Table 1. Age Distribution and Type of GTD

\begin{tabular}{lll}
\hline \multirow{2}{*}{ Age range } & H.Mole & Choriocarcinoma \\
\cline { 2 - 3 } & Frequency (\%) & Frequency (\%) \\
\hline $15-19$ & $21(30.4)$ & ----- \\
$20-24$ & $16(23.2)$ & $4(11.8)$ \\
$25-29$ & $7(10.1)$ & $4(11.8)$ \\
$30-34$ & $5(7.2)$ & $1(2.9)$ \\
$35-39$ & $3(4.3)$ & $1(2.9)$ \\
$40-44$ & $6(8.7)$ & $3(8.8)$ \\
$45-49$ & $8(11.6)$ & $13(38.2)$ \\
$50-54$ & $2(2.9)$ & $7(20.6)$ \\
$55-59$ & $1(1.4)$ & $1(2.9)$ \\
TOTAL & $69(100)$ & $34(100)$ \\
\hline
\end{tabular}

Table 2. Parity Distribution of GTD

\begin{tabular}{lll}
\hline Parity & Frequency & Percentage \\
\hline $0-1$ & 39 & 37.9 \\
$2--3$ & 20 & 19.4 \\
$4-5$ & 18 & 17.5 \\
$>5$ & 26 & 25.2 \\
TOTAL & 103 & 100 \\
\hline
\end{tabular}

Table 3. Ethnic Distribution of Patients

\begin{tabular}{lll}
\hline Ethnic group & Frequency & Percentage \\
\hline Hausa & 60 & 58.3 \\
Igbo & 11 & 10.7 \\
Fulani & 13 & 12.5 \\
Yoruba & 5 & 4.9 \\
Others & 14 & 13.6 \\
TOTAL & 103 & 100 \\
\hline
\end{tabular}


Table 4. Clinical Presentation of Patients

\begin{tabular}{lll}
\hline Symptoms & Frequency & Percentage \\
\hline Vaginal bleeding & 103 & 100 \\
Abdominal swelling & 52 & 50.5 \\
Excessive vomiting & 40 & 38.8 \\
Lower abdominal pain & 20 & 19.4 \\
Passage of vesicles & 11 & 10.7 \\
Cough & 7 & 6.8 \\
Dyspnoea & 5 & 4.9 \\
\hline
\end{tabular}

Majority of the patients $60(58.3 \%)$ were Hausas, $11(10.7 \%)$ were Igbos while 5(4.9\%) were Yorubas. The most common presenting symptom was vaginal bleeding occurring in all the cases, while anaemia defined as haemoglobin $<10 \mathrm{~g} / \mathrm{dl}$ was the most common complication. The antecedent pregnancy among the cases of choriocarcinoma were hydatidiform mole in 18 cases (52.9\%), miscarriage in 10 cases $(29.4 \%)$ and ectopic pregnancy in 1 case $(3.0 \%)$ and full term pregnancy in $5(14.7 \%)$ patients. Suction evacuation and follow up $(67.0 \%)$ was the mode of treatment in all cases of molar pregnancy only. Only the cases of choriocarcinoma (33.0\%) had chemotherapy and follow up, 11 cases $(32.4 \%)$ had single agent (Methotrexate), while 23 cases $(67.6 \%)$ had multiagent chemotherapy using Methotrexate, Actinomycin-D, and Cyclophosphamide (MAC). Twenty four patients (23.3\%) had regular follow up, 52(50.5\%) were irregular and $27(26.2 \%)$ did not turn up. There were seven maternal deaths in this study, given a case fatality of $6.8 \%$.

\section{Discussion}

The prevalence of GTD in this study was 4.5 per 1000 deliveries. This is comparable to 4.7 per 1000 deliveries in Nnewi and 3.58 per 1000 deliveries in Abakaliki from Southeast Nigeria ${ }^{6,16}$. However, It is much higher than incidences of 1 per $1000,1.3$ per 1000 , and 2 per 1000 pregnancies reported in the United States, the United Kingdom and Japan respectively ${ }^{3,8,23}$. The reason for low prevalence in industrialized countries compared to developing countries may be due to differences in the denominators (per pregnancies versus per deliveries) and most studies in developing countries were hospital based ${ }^{17}$.

Majority $69(66.9 \%)$ of GTD were hydatidiform mole which was similar to other studies ${ }^{4,16,17,23}$. GTD was commoner at the extremes of reproductive age. Hydatidiform mole was high $37(53.6 \%)$ in those aged 24 years and below, while choriocarcinoma was high $13(38.2 \%)$ in 45 - 49 years age group. The reason for this difference is not clear but Bugti QA et al. and Obiechina NJA et al. noted similar trend $^{18,19}$. This study did not find significant statistical difference in prevalence of GTD among the three major ethnic groups (Hausa, Igbo and Yoruba) in Nigeria. However, this is an institutional study with a small sample size and may not be a good representative of the whole nation. As such, establishment of GTD central registry across the country will help to resolve this issue. The most common presenting symptom was vaginal bleeding occurring in all the cases. This was noted in other studies ${ }^{6,16}$. Anaemia defined as haemoglobin level $<10 \mathrm{~g} / \mathrm{dl}$ was the most common complication and same had been reported by Ocheke et al. ${ }^{9}$ and Mbamara SU et $\mathrm{al}^{6}$. This may not be unrelated to late presentation, persistent vaginal bleeding and effects of chemotherapy. Suction evacuation $(67.0 \%)$ was the commonest form of treatment offered to those with GTD in AKTH. This method is currently advocated because it allows rapid evacuation of the uterus, provides specimen for histology and reduces the chance of trophoblastic tissue embolisaton $^{6,20,21}$. Follow-up of the patients was carried out by clinical examination, serum $\beta$-hCG level, and 3 monthly chest $\mathrm{X}$ - ray in persistent cases. Initial, follow up was carried out weekly till the $\beta$-hCG level was not detectable followed by monthly monitoring for 6-24 months. Chemotherapy was indicated in cases of persistent rise or plateau of $\beta$-hCG and in cases of choriocarcinoma. Patients with nonmetastatic (stage I) and low-risk metastatic (stages II and III, score $<7$ ) GTN were treated with single-agent methotrexate, while those with high-risk metastatic GTN (stage IV and stages IIIII score $\geq 7$ ) were treated initially with multi-agent chemotherapy. Suction evacuation and follow up (67.0\%) was the mode of treatment in all cases of molar pregnancy only. Only the cases of choriocarcinoma (33.0\%) had chemotherapy and follow up; 11 cases $(32.4 \%)$ had single agent (Methotrexate), while 23 cases $(67.6 \%)$ had multiagent chemotherapy using Methotrexate, Actinomycin-D, and Cyclophosphamide (MAC). The high rate of post molar GTN in this study was because most cases managed were referred, from other hospital either with histology result of choriocarcinoma or on account of persistent high $\beta$-hCG and/ or vaginal bleeding following suction evacuation. Twenty four patients $(23.3 \%)$ had regular follow up, 52(50.5\%) were irregular and $27(26.2 \%$ ) did not turn up for follow up. This poor follow up may be as a result of poverty, cultural attitudes and inadequate health education. There were seven maternal deaths in this study, given a case fatality of $6.8 \%$ which was higher than $3.3 \%$ and $0.8 \%$ from Pakistan and Argentina respectively ${ }^{17,22}$, but much lower than similar studies in Nigeria ${ }^{2,6,16}$. This high rate of mortality in this study may be due to late presentation and inadequate treatment because of poor follow up.

\section{Conclusion}

The incidence of GTD in this study was 4.5 per 1000 deliveries. Vaginal bleeding was the commonest presenting symptom. Early diagnosis and appropriate treatment of this disease has an excellent prognosis, while late presentation was associated with high maternal mortality as found in this study.

\section{References}

[1] Seckl MJ, Sebire NJ, Berkowitz RS. Gestational trophoblastic disease. Lancet. 2010 Aug 28; 376(9742):717-29 
[2] Eniola OA, Mabayoje P, Ogunniyi SO. Hydatidiform mole in Ile-Ife, Nigeria: a 10-year review. J Obstet Gynaecol. 2009 May;29(4):322

[3] Yakasai IA, Adamu N, Galadanchi HS. Ruptured tubal molar pregnancy. Niger J Clin Pract 2012;15:491-3

[4] Nkyekyer K. Gestational Trophoblastic Disease. In: Comprehensive Gynaecology In The Tropics.Kwawukume EY,Emuveyan EE (Eds).2005;498-511

[5] Audu BM, Takai IU, Chama CM, Bukar M, Kyari O. Hydatidiform mole as seen in a university teaching hospital: a 10 -year review.

[6] Mbamara S.U, Obiechina NJA, Eleje G.U, Akabuike C.J, Umeononihu O.S. Gestational Trophoblastic Disease in Tertiary Hospital Nnewi Southeast Nigeria. Niger Med. J. 2009; 50(4):

[7] Sebire N J, Seckl M J Gestational trophoblastic disease: current management of hydatidiform mole. BMJ 2008; 337:1193.

[8] Paola A. Gestational Trophoblastic Disease.In: Current diagnosis \& treatment obstetrics and gynaecology. Alan H.D,Lauren N, Murphy TG,Neri L (Eds). $10^{\text {th }}$ edition McGraw Hill,New York. 2007;885-895

[9] Ocheke AN, Jonah M, and Alexander OU. Hydatidiform mole in Jos, Nigeria. Niger Med J. 2011 Oct-Dec; 52(4): 223-226

[10] Smith HO, Kohorn E, Cole LA. Choriocarcinoma and gestational trophoblastic disease. Obstet Gynecol Clin North Am. Dec 2005;32(4):661-84

[11] Richa S. Hydatidiform Mole. Bedside Obstetrics \& Gynaecology. First edition 2010.Jaypee brother Medical Publishers (P) LTD. New Delhi.p135- 148.

[12] Soper JT. Gestational trophoblastic disease. Obstet Gynecol. Jul 2006; 108(1):176-87

[13] John RL. Gestational trophoblastic disease I:epidemiology, pathology, clinical presentation and diagnosis of gestational trophoblastic disease, and management of hydatidiform mole. Am J of Obstet Gynecol. 2010; 203(6): 531-539
[14] Foulmann K, Guastalla JP, Caminet N. What is the best protocol of single-agent methotrexate chemotherapy in nonmetastatic or low-risk metastatic gestational trophoblastic tumors? A review of the evidence. Gynecol Oncol. Jul 2006;102(1):103-10.

[15] Cavaliere A, Ermito S, Dinatale A, Pedata R. Management of molar pregnancy. Journal of Prenatal Medicine. 2009; 3 (1): $15-17$.

[16] Anuma ON, Umeora OUJ, Obuna JA, Agwu UM. Profiling Gestational Trophoblastic Disease in a Tertiary Hospital in South-East Nigeria. Niger J Clin Pract. 2008 Jun;11(2):134-8

[17] Khairunnisa N, Gulfareen H, Nizamuddin M, Ambreen H. Gestational Trophoblastic Disease: Experience at Nawabshah Hospital. J Ayub Med Coll Abbottabad 2009; 21(1) 94-7.

[18] Bugti QA, Baloch N, Baloch MA. Gestational Trophoblastic Disease in Quetta. Patistan J. Med. Res. 2005; 44(2):200 - 4.

[19] Obiechina NJA, Udigwe GO, Obi RA. Molar pregnancy a ten yrar review at Onitsha Nigeria. Journal of Medical Investigation and Practice(JOMIP)2001;13:26-31

[20] Ben-Arie A, Deutsch H, Volach V, Peer G, Husar M, Lavie O, et al. Reduction of post molar gestational trophoblastic neoplasm by early diagnosis and treatment. J Reprod Med. $2009 ; 54: 151-4$

[21] Nevin J. Gestational trophoblastic disease. In: Bloch B, Dehaeck K, Soeters R, editors. Manual of Practical Gynecological Oncology. London: Chapman and Hall Medical; 1995. pp. 130-46.

[22] Bianconi MI, Otero S, Moscheni O, Alvarez L, Storino C, Jankilevich G. Gestational trophoblastic disease:a 21-year review of the clinical experience at an Argentinean public hospital. J Reprod Med. 2012; 57(7-8):341-9.

[23] RCOG Green-top Guideline No.38, February 2010: THE MANAGEMENT OF GESTATIONAL TROPHOBLASTIC DISEASE. 